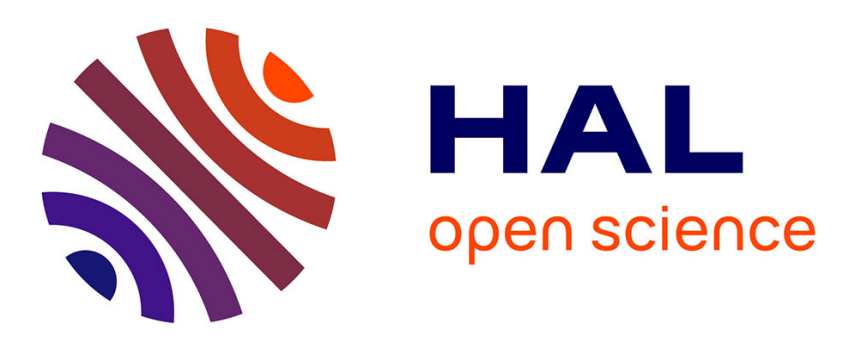

\title{
Self-Radiolysis of Tritiated Water Stored in Zeolites 4A: Production and Behavior of $\mathrm{H} 2$ and $\mathrm{O} 2$
}

Laëtitia Frances, Mikaël Douilly, Manuel Grivet, Didier Ducret, Marc

Theóbald

\section{- To cite this version:}

Laëtitia Frances, Mikaël Douilly, Manuel Grivet, Didier Ducret, Marc Theóbald. Self-Radiolysis of Tritiated Water Stored in Zeolites 4A: Production and Behavior of H 2 and O 2. Journal of Physical Chemistry C, 2015, 10.1021/acs.jpcc.5b10243 . hal-01367658

\section{HAL Id: hal-01367658 https://hal.science/hal-01367658}

Submitted on 19 Sep 2016

HAL is a multi-disciplinary open access archive for the deposit and dissemination of scientific research documents, whether they are published or not. The documents may come from teaching and research institutions in France or abroad, or from public or private research centers.
L'archive ouverte pluridisciplinaire HAL, est destinée au dépôt et à la diffusion de documents scientifiques de niveau recherche, publiés ou non, émanant des établissements d'enseignement et de recherche français ou étrangers, des laboratoires publics ou privés. 


\title{
Self-Radiolysis of Tritiated Water Stored in Zeolites
}

\section{A: Production and Behaviors of $\mathrm{H}_{2}$ and $\mathrm{O}_{2}$}

\author{
Laëtitia Frances ${ }^{\dagger *^{*}}$, Mikaël Douilly ${ }^{\dagger}$, Manuel Grivet $t^{\dagger}$, Didier Ducret $t^{\dagger}$, Marc Théobald ${ }^{\dagger}$ \\ ${ }^{\dagger}$ CEA Valduc, Département Tritium, 21120 Is-Sur-Tille, France \\ * Laboratoire Chrono-Environnement, UMR CNRS 6249, Université de Bourgogne Franche- \\ Comté, 25030 Besançon Cedex, France
}

KEYWORDS:

Hydrogen production

Hydrogen recombination

Molecular sieve

Confined Tritium

Adsorbed water

Energy transfers

Hydroxyl 


\section{ABSTRACT:}

Radiolysis of confined water and self-radiolysis of tritiated water gives rise to several unanswered questions. To take into account this double specificity, we studied systems of zeolites 4A containing tritiated water at different water loading ratios. Two tritiated water were synthesized at the volumetric activities of $27 \mathrm{TBq} \cdot \mathrm{L}^{-1}$ and $60 \mathrm{TBq} \cdot \mathrm{L}^{-1}$. For each one, five samples were prepared, differentiated by their water loading ratios, expressed in percentage, close to 4, 7 , 11,14 and $19 \%$. The study of the radiolysis in those systems revealed a double role of zeolites 4A: first, they increase the decomposition of water. Then they enhance the recombination of the major stable radiolytic products detected. We actually evidenced a total recombination between $\mathrm{H}_{2}$ and $\mathrm{O}_{2}$ which is catalyzed by the zeolites.

\section{INTRODUCTION}

Zeolites are a diversified class of natural or synthetic porous materials. The 218 different types of zeolites listed $^{1}$ are implied in many applications like catalysis ${ }^{2,3}$, filtration ${ }^{4,5}$, and isotopic separation $^{6}$. Zeolites 4 A, belonging to the class LTA, are hydrophilic and can be used to store tritiated water, generated along the manipulation of Tritium, for nuclear applications like ITER ${ }^{7}$. The development of such a reactor requires safe solutions to store tritiated water.

Zeolites $\mathrm{A}$ are built from tetrahedrons $\mathrm{SiO}_{4}$ and $\mathrm{AlO}_{4}{ }^{8}$. The framework negative charge, induced by the valence of Aluminum, is compensated by the presence of cations. Their nature and their location depends on the type of zeolite A. In zeolites 4A, the negative charge of the framework is compensated by the presence of 12 monovalent Sodium cations per unit cell: 
$\left[\mathrm{Na}_{12}\left(\mathrm{SiO}_{4}\right)_{12}\left(\mathrm{AlO}_{4}\right)_{12}\right]$. Zeolites 4A can adsorb spontaneously water. When they are saturated, 27 or 28 molecules of water ${ }^{9,10}$ are confined in each unit cell. The crystallographic structure of zeolites A is composed of sodalites called $\beta$ cages. They have the shape of truncated octahedrons with an internal diameter of $6.6 \AA$. Sodalite cages are disposed in a cubic arrangement. Another type of nanoporous cavities is so created in the center of this array, octahedron-shaped too and called supercage or $\alpha$ cage. In spite of some slight differences depending on authors, in each unit cell, the given number of water molecules adsorbed in $\beta$ cages, obtained by simulation is 4 or 5 , and the number of molecules located in $\alpha$ cages is obtained between 20 and $23^{9-11}$.

Based on FTIR or thermogravimetric results, the adsorption of water is described as an heterogeneous phenomenon ${ }^{12,13} \cdot \beta$ cages are filled first and adsorbed water presents a very strong interaction with cations and interacts through hydrogen bonds with the Oxygen atoms of the framework. Then $\alpha$ cages are filled with water molecules covering the internal surface and whose interaction strength decreases. The next adsorbed water molecules, completing the filling of supercages, are sometimes called "bulk-like" water since they do not undergo direct interaction with zeolites, and show physical and chemical properties close to the bulk-water ones. Finally a few molecules can be adsorbed in non-crystallographic volumes, like spaces between grains, created during the shaping of zeolites, after adjunction of a binder. The location of water molecules and the interaction between zeolite and water so evolve along water adsorption. As a consequence we chose to focus our experiments on the influence of Water Loading Ratio (WLR), given as a percentage and corresponding to the mass of adsorbed water divided by the mass of dried zeolites. 
The radiolysis of water has been widely studied, in particular because it occurs in many applied situations, like in medicine ${ }^{14,15}$ or food-processing industry ${ }^{16}$. The particular case of selfradiolysis of tritiated water has also been described several times ${ }^{17,18}$. Nevertheless, the radiolysis of confined water shows differences compared to the bulk water one ${ }^{19-23}$, and gives raise to many remaining questions without definitive answers concerning the role of the adsorbent. An increase in the production rate of hydrogen is often described in presence of interfaces such as oxides or internal surfaces created by the nanopourous volumes of zeolites. Hydroxyl radicals have been designed to influence the hydrogen release as they play a major role in its recombination ${ }^{20,24}$. Nevertheless, results considering both the self-radiolysis of tritiated water and the confinement in zeolites $4 \mathrm{~A}^{25}$ are sporadic, incomplete and are not representative of the irradiation conditions applied in storage situations.

We focused then both on the irradiation induced by tritiated water and on the radiolysis of water confined in zeolites $4 \mathrm{~A}$. We took a special interest in the influence of the Water Loading Ratio on radiolysis, because of the heterogeneity of water adsorption.

\section{EXPERIMENTAL SECTION}

\section{Dehydration of zeolites 4A}

Synthetic and hydrophilic zeolites 4A were supplied by Molsiv Adsorbents and contain a binder used along the synthesis of zeolites to improve their mechanical properties. It is chemically inert and only reduces the global capacity of zeolites 4A for water adsorption (the binder is not porous). The WLR can reach $19.6 \%$ at saturation according to the supplier. 
Zeolites 4A were provided in the form of pebbles, with a measured diameter of 2,0 $0,2 \mathrm{~mm}$. They were used in this form for the follow-up of self-radiolysis of tritiated water.

About $240 \mathrm{~g}$ of saturated zeolites, equilibrated with atmospheric water, were introduced in $640 \mathrm{~cm}^{3} 316 \mathrm{~L}$ stainless steel containers. Zeolites were degassed and dehydrated by a two steps conditioning. First, zeolites were heated at $400^{\circ} \mathrm{C}$ during 7 hours, under Argon flow, to avoid an exposure of the turbomolecular pump to high quantities of water vapor. Then, they were heated at $400^{\circ} \mathrm{C}$ under dynamical secondary vacuum during 7 hours. Because we used zeolites initially equilibrated with atmosphere, we assumed an initial WLR of $19.6 \%$ which allows calculating the respective masses of zeolites and water. The complete dehydration, also called activation, has been checked by weighting before and after the two-step activation.

\section{Synthesis of chemically pure tritiated water}

We synthetized chemically pure tritiated water by isotopic exchange. $250 \mathrm{~cm}^{3}$ and $300 \mathrm{~cm}^{3}$ of non-tritiated milli-Q water were introduced in two $560 \mathrm{~cm}^{3} 316 \mathrm{~L}$ stainless steel containers. We then introduced gaseous $\mathrm{T}_{2}\left(90 \% \mathrm{~T}_{2}, 5 \% \mathrm{~N}_{2}, 2 \%{ }^{3} \mathrm{He}, 1 \% \mathrm{O}_{2}, 1 \% \mathrm{DT}, 1 \% \mathrm{HT}\right)$ at a pressure of about 800 mbar. Then, gas phase has been sampled in $10 \mathrm{~cm}^{3}$ flasks all along the isotopic exchange and analyzed by high resolution mass spectrometry, carried out with a Finigan Mat 271 apparatus, giving relevant results (about $1 \%$ precision, depending on gas and on the analysis) until a detection limit of $100 \mathrm{ppm}$. The quantity of Tritium atoms lost in gaseous phase was considered to be the same than the quantity won in the liquid phase (the loss of matter due to sampling in $10 \mathrm{~cm}^{3}$ flasks was taken into account). Based on this assumption, we calculated the volumetric activity of water. When water activity had reached the target, isotopic exchange was stopped by eliminating the gaseous phase. Two synthesis were realized leading to calculated 
activities of $27 \mathrm{TBq} . \mathrm{L}^{-1}$ and $60 \mathrm{TBq} . \mathrm{L}^{-1}$, experimentally checked by liquid scintillation. It corresponds to isotopic ratios of respectively 0.068 and $0.15 \%$. Those activities were chosen to be representative of water produced by gas clean-up systems. The synthesis of the Low Volumetric Activity (LVA) water required 21 days. The synthesis of the High Volumetric Activity (HVA) water required 93 days of isotopic exchange. During this second synthesis the gaseous phase was replaced after 55 days with rich Tritium gas $\left(90 \% \mathrm{~T}_{2}\right)$ in order to accelerate the isotopic exchange. Actually, after those 55 days the concentration of $\mathrm{T}_{2}$ in the gaseous phase decreased from about $90 \%$ to $15 \%$, leading to a slow-down of the isotopic exchange.

\section{Adsorption of tritiated-water in previously dehydrated zeolites $4 \mathrm{~A}$}

Tritiated water was then adsorbed in zeolites $4 \mathrm{~A}$ by an exposition of dried samples to tritiated water vapor. This process avoids the direct manipulation of liquid tritiated water, highly contaminating in case of contact, despite gloves wearing. The Water Loading Ratio (WLR), depending on exposition time of zeolites to water vapor, was previously determined with non tritiated water. For each one of the two tritiated water synthesized, we targeted five WLR: 4, 7, $11,14 \%$ and saturation. The real WLR that we re-measured by weighting after adsorption are given in the Table 1. We used Argon to inert the gaseous phase of the containers, and as a cover gas for the subsequent analysis by mass spectrometry. We introduced a 420 mbar Argon pressure after the water adsorption in zeolites. We conditioned an additional control-container without any cover gas, containing zeolites 4A saturated with the HVA water (table 1). 
Table 1: Characteristics of the eleven systems conditioned to follow self-radiolysis of adsorbed tritiated water.

\begin{tabular}{|c|c|c|c|c|c|c|c|c|c|c|c|}
\hline \multirow[b]{2}{*}{$\begin{array}{l}\text { Mass of dried } \\
\text { zeolites }(\mathrm{g})\end{array}$} & \multicolumn{5}{|c|}{ Low Volumetric Activity (27 TBq.L ${ }^{-1}$ ) } & \multicolumn{6}{|c|}{ High Volumetric Activity (60 TBq.L ${ }^{-1}$ ) } \\
\hline & 199.95 & 199.98 & 199.99 & 201.39 & 200.98 & 202.74 & 199.95 & 201.90 & 202.74 & 202.39 & 200.28 \\
\hline $\begin{array}{l}\text { Mass of adsorbed } \\
\text { water }(\mathrm{g})\end{array}$ & 8.1 & 15.6 & 23.6 & 27.7 & 37.1 & 9.2 & 14.8 & 23.1 & 27.1 & 37.2 & 37.6 \\
\hline $\begin{array}{c}\text { Water Loading } \\
\text { Ratio }(\%)\end{array}$ & 4.1 & 7.8 & 11.8 & 13.7 & 18.5 & 4.5 & 7.4 & 11.4 & 13.4 & 18.4 & 18.8 \\
\hline Cover gas & $\mathrm{Ar}$ & Ar & Ar & $\mathrm{Ar}$ & $\operatorname{Ar}$ & $\mathrm{Ar}$ & $\mathrm{Ar}$ & $\mathrm{Ar}$ & $\mathrm{Ar}$ & $\operatorname{Ar}$ & none \\
\hline
\end{tabular}

\section{Self-radiolysis of tritiated water confined in zeolites $4 \mathrm{~A}$}

All the eleven containers were regularly sampled, allowing us following the composition of their gas phase during the radiolysis of confined water, determined by high resolution mass spectrometry and given as volumetric percentages.

A pressure transducer was assigned to each container, allowing a continuous recording of the pressure, with a frequency of one point per minute, thanks to a 20 input Honeywell Multitrend SX recording device. The temperature in four different points of the manipulation area was also measured with 4 PTX 100 probes, and was also recorded. Consequently, based on the perfect gas law, we were able to calculate the total amount of matter in the gas phase of each container all along the experiments.

The volume of each container had been previously measured by ten Helium releases from a known pressure in a known volume. Helium releases had also been performed in containers after their filling with a known mass of dried zeolites. In this way the volumetric mass of zeolites $4 \mathrm{~A}$ had been determined and subtracted. The volume of sodalite cages and supercages has been deduced as well, depending on the water loading ratio. As a result the volume accessible to gases 
was estimated from the free volume of the container and takes into account the volume occupied by dried zeolites and water adsorbed. The standard deviation of the ten volumes measured and calculated for each container was used to estimate the uncertainty on the free volume, considered to be $5 \mathrm{~cm}^{3}$. The composition of the gas phase was calculated from the total quantity of matter in the gas phase, weighted by the measured percentage of each compound. The high resolution mass spectrometry allows us detecting and quantifying ${ }^{3} \mathrm{He},{ }^{4} \mathrm{He}, \mathrm{H}_{2}, \mathrm{~T}_{2}, \mathrm{D}_{2}, \mathrm{HT}, \mathrm{HD}, \mathrm{DT}, \mathrm{O}_{2}$, $\mathrm{CT}_{4}, \mathrm{CH}_{4}, \mathrm{CO}_{2}$ and $\mathrm{N}_{2}+\mathrm{CO}$. We considered that the amounts of gas that we measured were "released" amounts rather than "produced" amounts to stay careful regarding trapping of radiolytic species, even if very unlikely. As an example, zeolites $4 \mathrm{~A}$ under 15 bar pressure of $\mathrm{H}_{2}$ adsorb only $1.4 \%$ of their mass at $-196{ }^{\circ} \mathrm{C}$ and $0.3 \%$ at $270{ }^{\circ} \mathrm{C}^{26}$.

An initial analysis reveals the gases released by the self-radiolysis of water alone, before its adsorption in zeolites. The result of this analysis is subtracted to the following analysis to only discuss the gas released by the radiolysis of adsorbed water. The major gas detected, except Argon, are $\mathrm{H}_{2}$, with percentages below $2 \%$ and $\mathrm{O}_{2}$ with percentages below $1 \%$. It was slightly higher only in the system containing the zeolites loaded at $7.8 \%$ with the low volumetric activity water, where $\mathrm{O}_{2}$ concentration reached $5 \%$. Regarding the stability of $\mathrm{N}_{2}$ amount all along the experiment, this was attributed to initial air traces. No special impact was noticed along the radiolysis.

\section{Energy deposition}

The energy deposited in each whole system is conditioned by the volumetric activity of water and the quantity of water adsorbed. The energy deposited is calculated with equation 1 , obtained by integrating the exponential decay law of Tritium. $E_{t_{0} \rightarrow t_{1}}$ is the energy deposited in the whole 
system, $E_{\beta^{-}}$the average energy of particles emitted by Tritium decay $(5.7 \mathrm{keV}), A_{v o l}$. the volumetric activity and $V$ the volume of water adsorbed, $t_{0}$ the date where water is adsorbed, $t_{1}$ the time elapsed from the beginning of radiolysis and $t_{1 / 2}$ the radioactive period of Tritium $\left(12.32\right.$ years $\left.=3.89 \times 10^{8} \mathrm{~s}^{27}\right)$.

$$
E_{t_{0} \rightarrow t_{1}}=E_{\beta^{-}} \times A_{v o l .} \times V \times \frac{-t_{1 / 2}}{\ln 2} \times\left[\exp ^{\frac{-\ln 2}{t_{1 / 2}} t_{1}}-1\right]
$$

The distribution of the primary energy deposition between zeolites and adsorbed water is frequently approximated to the mass proportions ${ }^{28,29}$.

\section{RESULTS}

\section{${ }^{3}$ He Release}

${ }^{3} \mathrm{He}$ is an interesting species as it is released by Tritium decay and is not a reactive gas. Moreover the quantity of Helium released can be calculated from the quantity of water adsorbed and its activity, according to the equation 2 , where $n_{\mathrm{He}(\mathrm{t})}$ is the quantity of ${ }^{3} \mathrm{He}$ produced in moles, after a duration $\mathrm{t}$ given in seconds, for an initial activity $\mathrm{A}_{0}$ in Becquerels and $\mathrm{Na}$ is the Avogadro number.

$$
n_{\mathrm{He}(t)}=\frac{A_{0} \times \frac{-t_{1 / 2}}{\ln 2} \times\left[\exp ^{\frac{-\ln 2}{t_{1 / 2}} t}-1\right]}{\mathrm{Na}}
$$

For two years of storage, ${ }^{3} \mathrm{He}$ release appears quite linearly-dependent on time and allows the calculation of a releasing rate. The experimental quantities of ${ }^{3} \mathrm{He}$ measured, represented on figure 1 and 2, are lower than the calculated ones. The missing quantity of ${ }^{3} \mathrm{He}$ represents about 
$20 \%$ of the theoretical ${ }^{3} \mathrm{He}$ release what is consistent with the quantity removed because of sampling.

Nevertheless, the experimental quantity of ${ }^{3} \mathrm{He}$ released by the system of zeolites containing $4.1 \%$ of LVA water is much lower than the one expected. It cannot be only explained by sampling. An increase of pressure of 230 mbar after 400 days has been measured in this container. It has been attributed to an airtightness failing in this system since a linear increase of the quantity of $\mathrm{N}_{2}$ and $\mathrm{O}_{2}$, in the proportion of air, has been revealed by gas phase analyses. The inconsistency of results for ${ }^{3} \mathrm{He}$ quantization in the system of zeolites $4 \mathrm{~A}$ with $4.1 \%$ of LVA water, despite a slow air entrance, shows that ${ }^{3} \mathrm{He}$ is a relevant probe of airtightness even if it is not a major gas released. ${ }^{3} \mathrm{He}$ quantization leads us to eliminate the leaking system, and to trust in the sufficient airtightness of the other ones.

\section{${ }^{3}$ He in Low Volumetric Activity (LVA) systems}

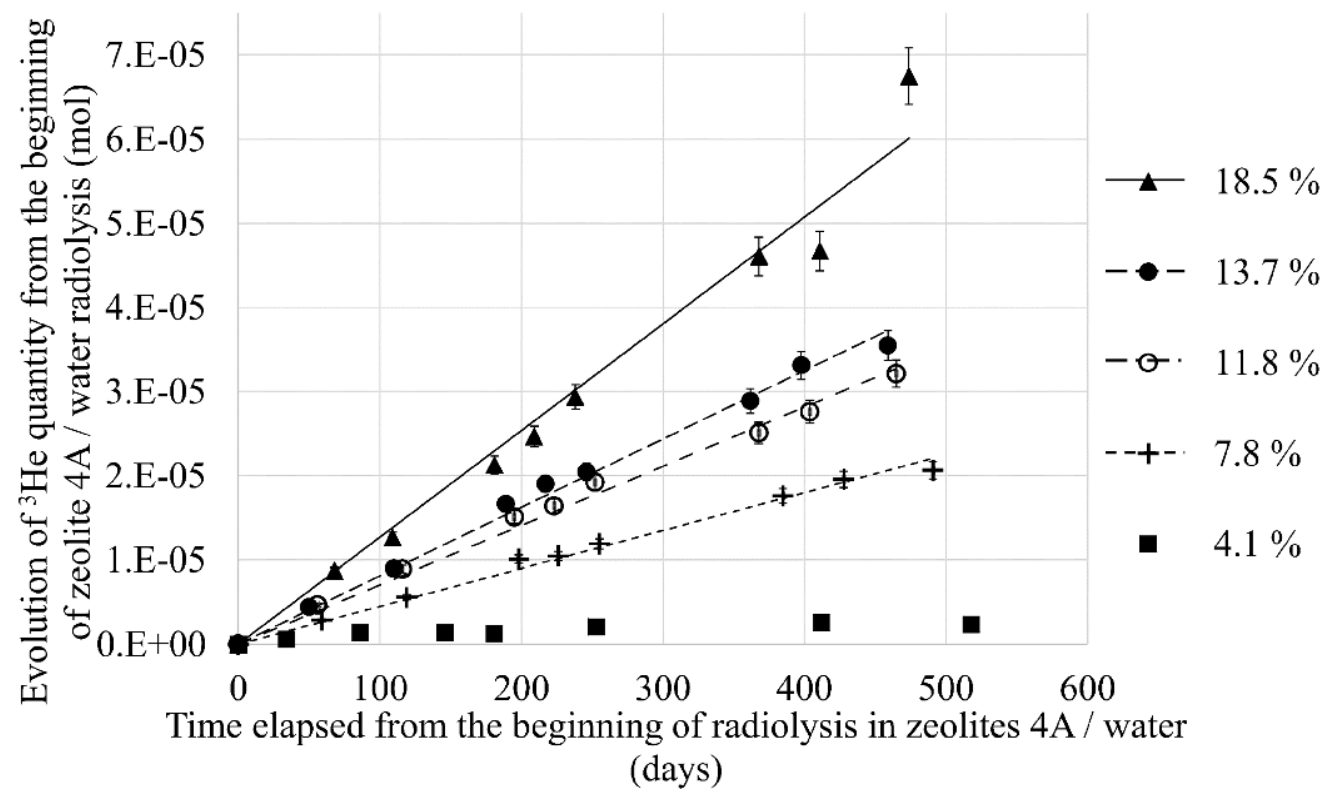

Figure 1: Release of ${ }^{3} \mathrm{He}$ along time in zeolites 4A containing Low Volumetric Activity water (LVA, $27 \mathrm{TBq} . \mathrm{L}^{-1}$ ), experimental values and interpolated production rates 


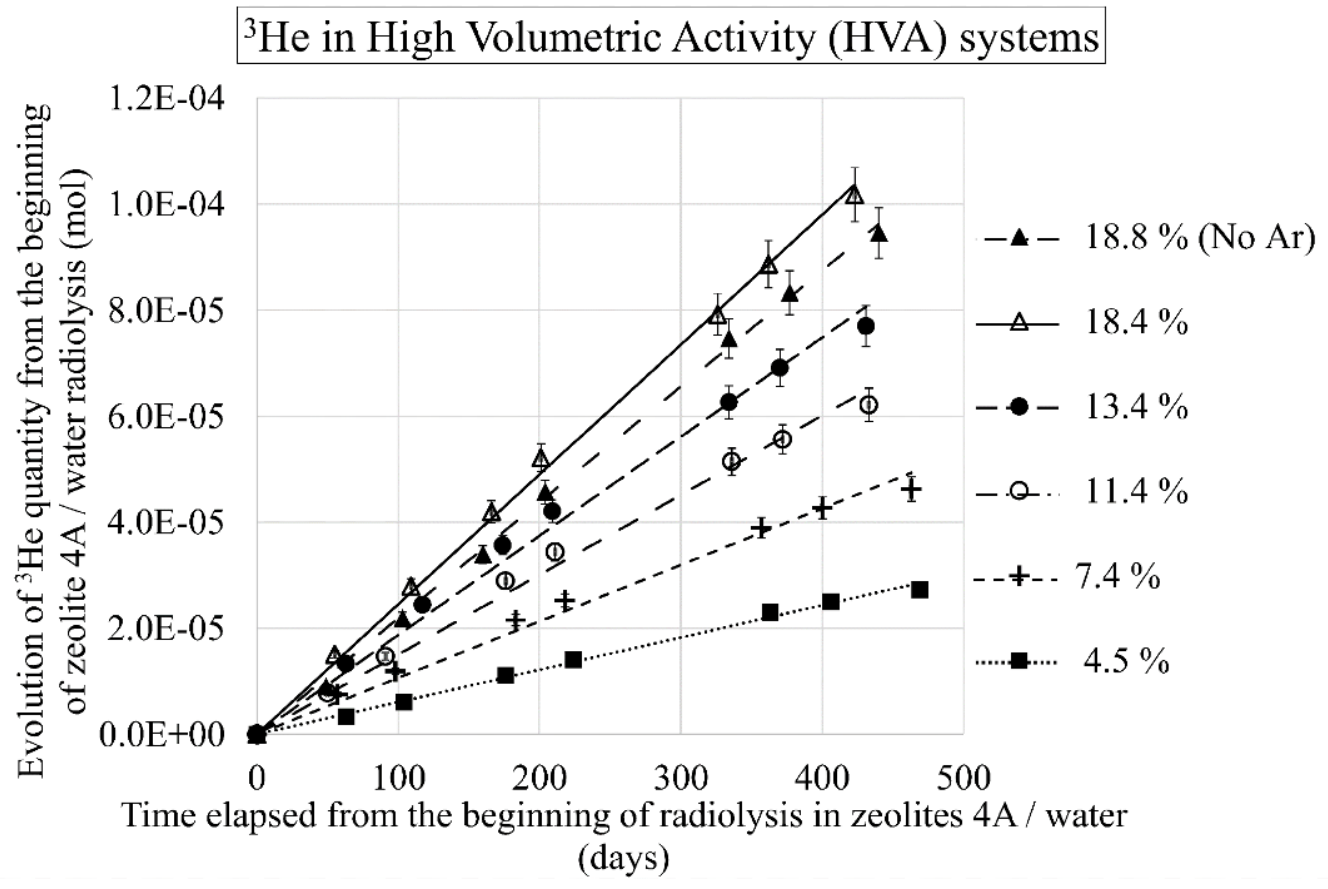

Figure 2: Release of ${ }^{3} \mathrm{He}$ along time in zeolites $4 \mathrm{~A}$ containing High Volumetric Activity water (HVA, $60 \mathrm{TBq} \cdot \mathrm{L}^{-1}$ ), experimental values and interpolated production rates

\section{Quantity of gaseous matter along the trials}

The first indicator of an evolution in gas phase is the quantity of matter, calculated all along the radiolysis in each system, based on pressure and temperature records. It is represented on figures 3 for HVA water systems. Lines are built from the minute per minute recording. Triangles allow to date sampling for analyses. Zeolites containing LVA water showed a similar behavior.

First, we observed an important decrease of the gaseous quantity of matter. The more the crystallographic volumes of zeolite $4 \mathrm{~A}$ are filled with water the lower the decrease is. It has been attributed to a slow diffusion of Argon in the zeolites. This hypothesis is based on the analysis 
results, showing that the quantity of matter for other gases is constant. Furthermore, such a decrease is not observed in the test container, whose gas phase is Argon-free.

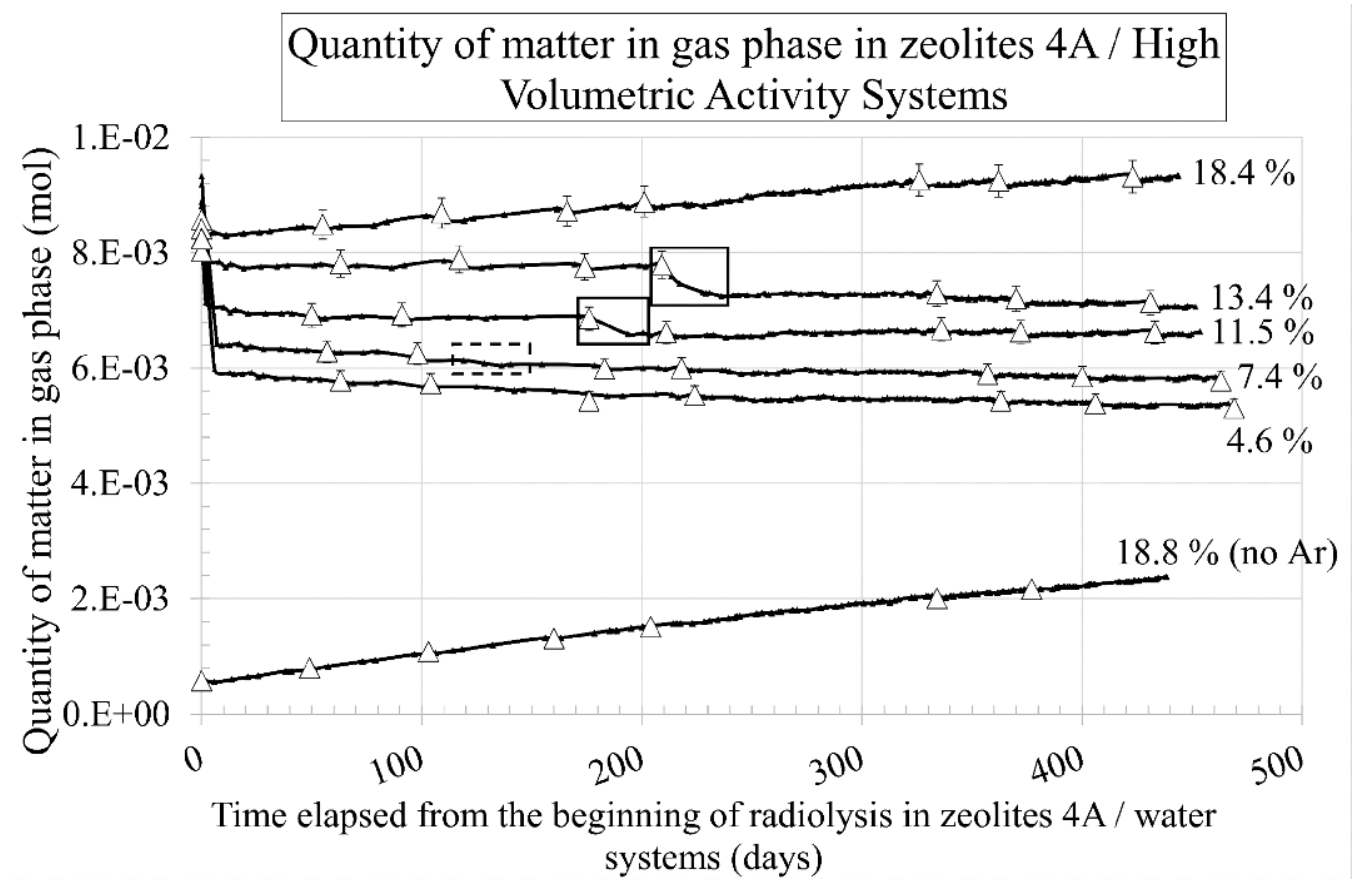

Figure 3: Quantity of gaseous matter in zeolite / HVA water systems depending on time elapsed, triangles are dating the analysis sampling. The percentages on the figure indicate the WLR of zeolites. Decreases not attributed to sampling are framed.

Then the gaseous quantity of matter increased for the highest WLR, and was almost stable for the lower ones. A significant drop is finally observed in the two HVA systems loaded at 11.5 and $13.4 \%$. A more discreet drop is also observed in the $7.4 \%$ system. This phenomenon is also noticed for LVA water, on the study period, when zeolites contain 11.8 and $13.7 \%$ of water (figure 4). We interpreted the behavior of the different systems based on the complete analyses of the gas phase composition. 


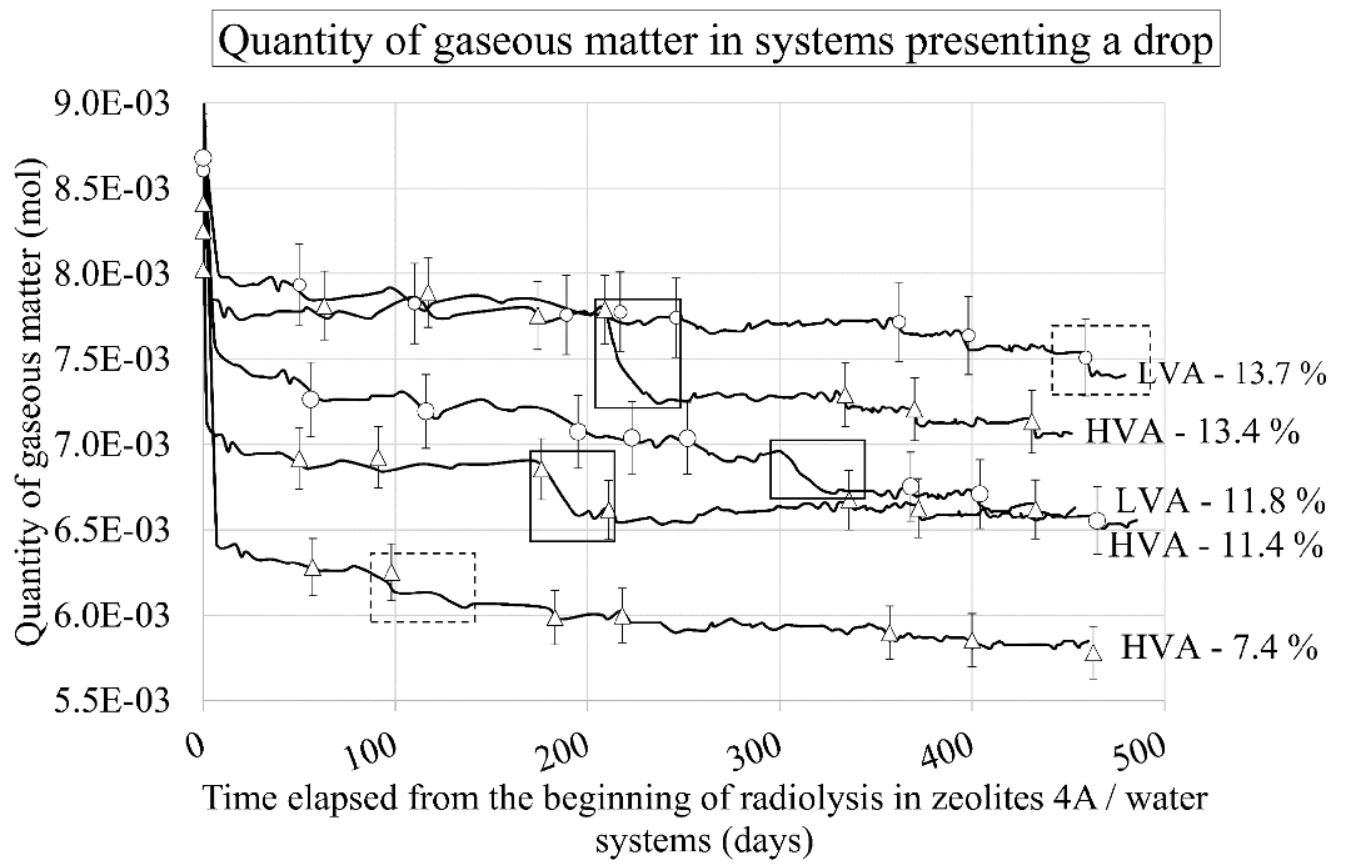

Figure 4: Quantity of gaseous matter in zeolite 4A / water systems concerned by a loss of gas non-attributed to sampling.

\section{Gaseous composition along trials}

The only two gases detected as a result of the water decomposition were $\mathrm{O}_{2}$ and $\mathrm{H}_{2} . \mathrm{H}_{2}$ was the only significant released isotopic form of Hydrogen. We never detected the form $\mathrm{T}_{2}$, and HT was only detected as traces in the test container (without Argon). It is consistent with the ratio of HTO to $\mathrm{H}_{2} \mathrm{O}$ species, calculated from volumetric activities.

We subtracted the result of the first analysis, carried out just after the water loading of zeolites, showing traces of $\mathrm{H}_{2}$ and $\mathrm{O}_{2}$, due to the self-radiolysis of liquid tritiated water, before its adsorption. In this way, we only took into account the radiolysis of confined water, after its adsorption in zeolites. Then quantities of $\mathrm{H}_{2}$ and $\mathrm{O}_{2}$ described on figures 5 to 7 are relative quantities and are slightly negative when a decrease is observed, in LVA systems containing 7.8 and $11.8 \%$ of water and in non-saturated HVA systems. Points are linked according to their 
values and to the total quantity of gaseous matter calculated from pressure and temperature in containers. Error bars are implemented considering the precision of the pressure and temperature sensors, the uncertainty on the free volume and the precision of each analysis. There are much higher for the only system not containing Argon due to its lower gas pressure.

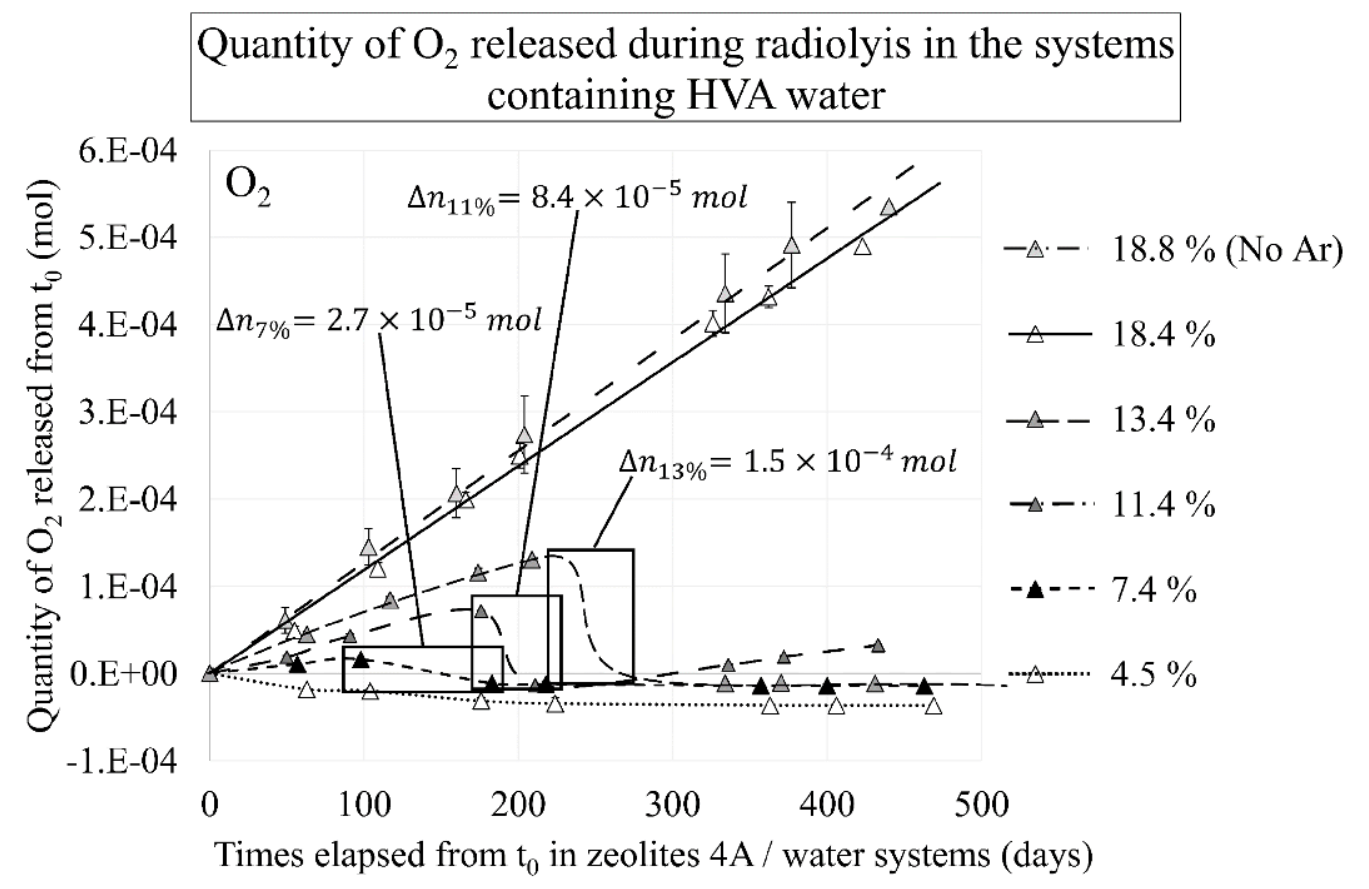

Figure 5: Relative quantity of $\mathrm{O}_{2}$ released by zeolites loaded with the HVA water, at different WLR. Periods of $\mathrm{O}_{2}$ loss are framed and quantity of $\mathrm{O}_{2}$ which reacts is indicated for the three systems concerned with this phenomenon. 


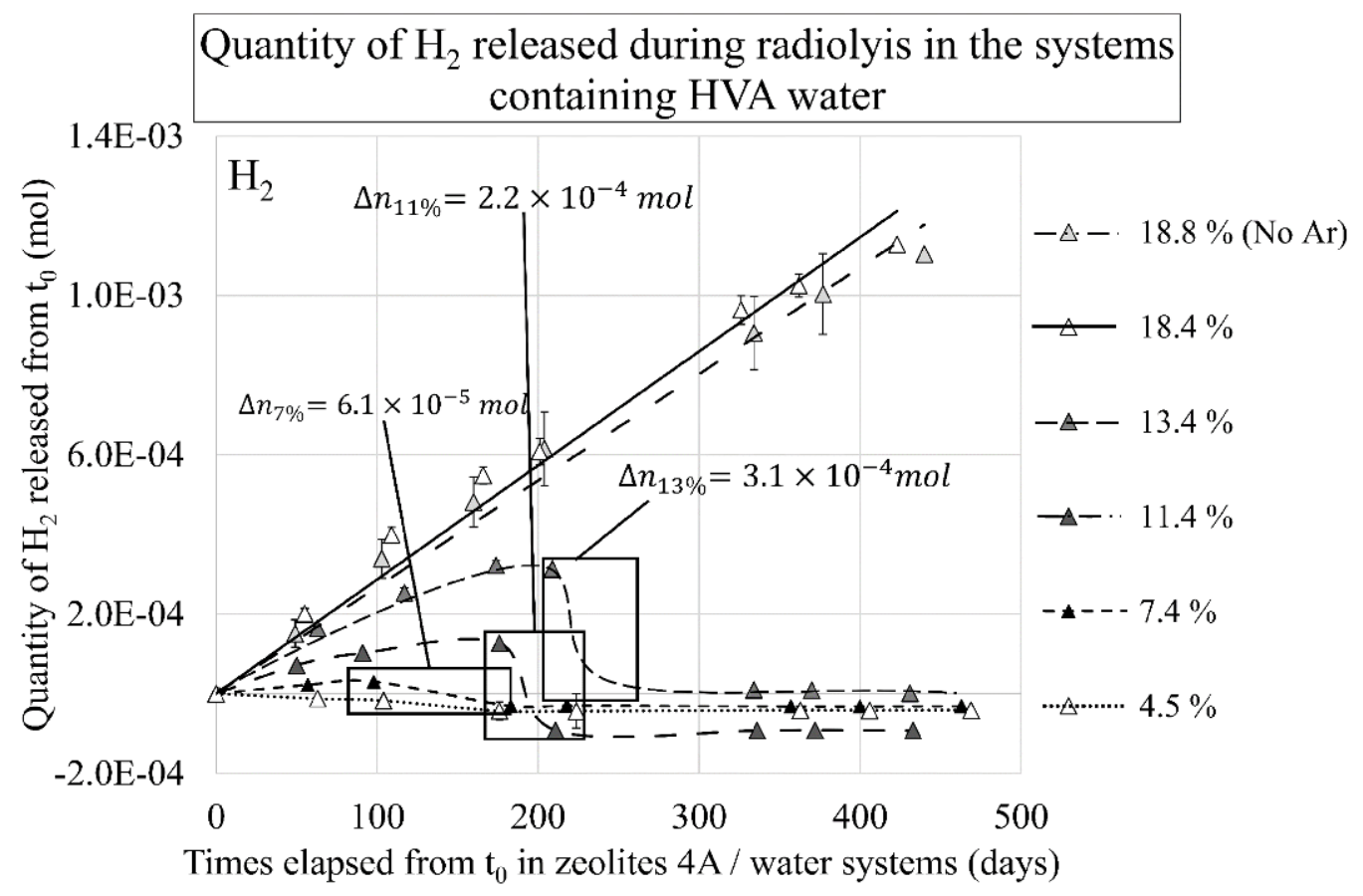

Figure 6: Relative quantity of $\mathrm{H}_{2}$ released by zeolites loaded with the HVA water, at different WLR. Periods of gas drop are framed and quantity of $\mathrm{H}_{2}$ which reacts is indicated for the three systems affected by this phenomenon. 


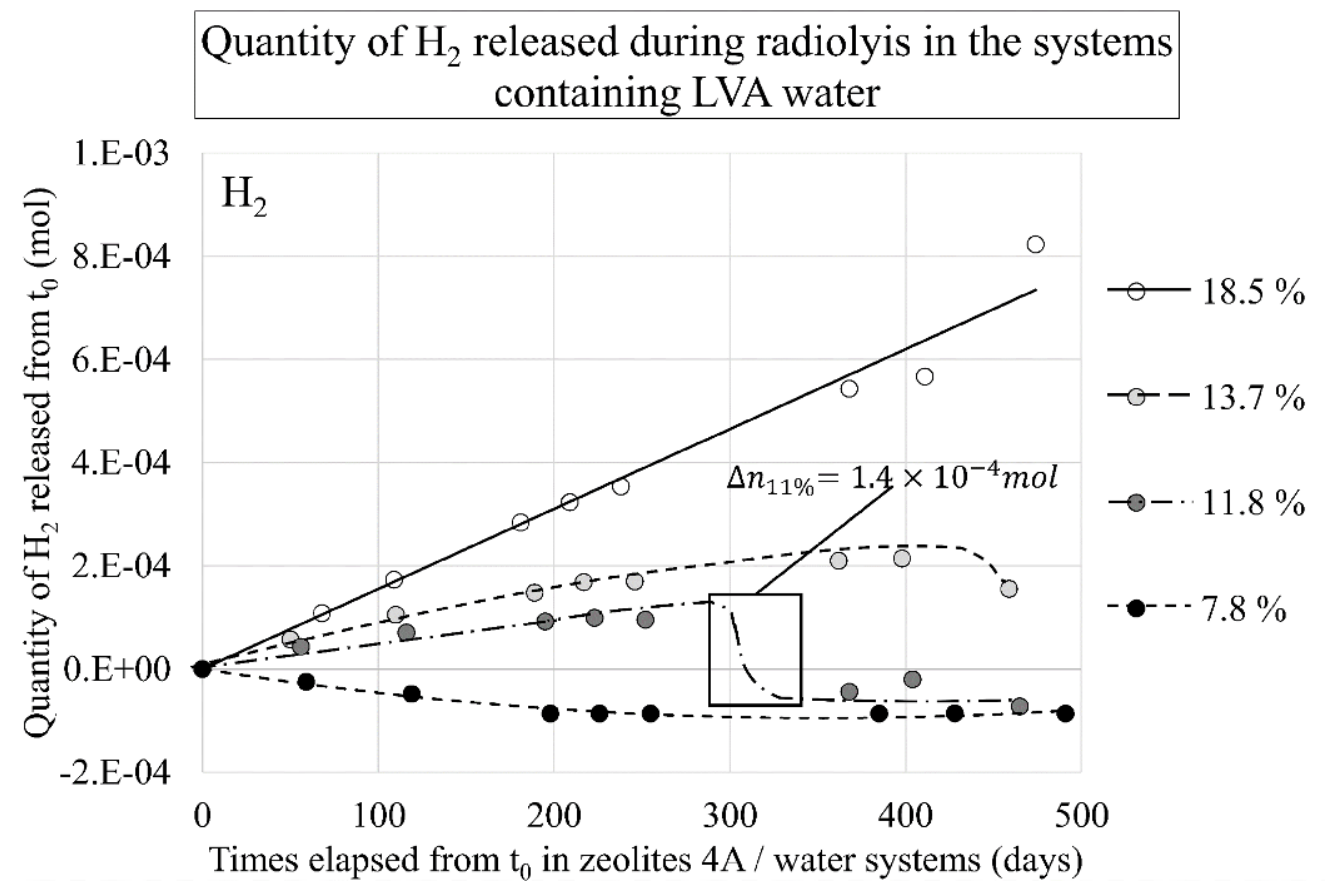

Figure 7: Relative quantity of $\mathrm{H}_{2}$ released by zeolites loaded with the LVA water, at different WLR. Periods of $\mathrm{H}_{2}$ loss are framed and the quantity which reacts is indicated for the three systems affected by this phenomenon.

The complete analyses confirmed that $\mathrm{H}_{2}$ and $\mathrm{O}_{2}$ are responsible for the evolution of the total quantity of gaseous matter presented on figures 3 and 4. The release of $\mathrm{H}_{2}$ and $\mathrm{O}_{2}$ appears to be linear along the time for systems saturated with water whatever the volumetric activity (figure 5 to figure 7. The release of $\mathrm{O}_{2}$ in LVA systems is similar to $\mathrm{H}_{2}$ one.). For the seven systems partially loaded with water, a total recombination of $\mathrm{H}_{2}$ and $\mathrm{O}_{2}$ is observed in four systems. One more is engaged, but is not over in the LVA system containing $13.7 \%$ of water (figure 7). Considering the proportion of $\mathrm{H}_{2}$ and $\mathrm{O}_{2}$ reacting (average ratio of 2.4), and the absence of new species in the gaseous phase, we propose a recombination leading to water. The lower the water loading ratio of zeolites is, the earlier the recombination occurs. We assume that it is so early for 
zeolites loaded at $4.5 \%$ with HVA water and zeolites loaded at $7.8 \%$ with LVA water, that no significant release of $\mathrm{H}_{2}$ and $\mathrm{O}_{2}$ are visible. For systems higher loaded, the initial release of hydrogen and oxygen happens.

As the WLR strongly conditions the quantity of gas released and the delay before they recombine, zeolites seem to play a major role on radiolysis of water first, and on the recombination which occurs next. Nevertheless, a more detailed discussion is required: WLR is linked to the coverage of the internal adsorption sites of zeolites, to the volumetric activity, to the primary energy deposition and its transfer from zeolite to water.

\section{DISCUSSION}

Zeolites 4A seem to favor water decomposition first and then water recombination. A related behavior has been evidenced for zeolites $5 \mathrm{~A}$ exposed to gamma radiations, and Tritium $\beta^{-}$ radiations $^{25}$. Hydrogen is first released with a radiolytic yield which is higher than the one obtained for free bulk water. Nevertheless, when zeolites are not saturated, the obvious quantity of hydrogen produced when the deposited dose increases downwardly inflects. This slowing down of hydrogen release can be attributed to a recombination phenomenon. The phenomenon that we measured is almost different, as an original total recombination between $\mathrm{H}_{2}$ and $\mathrm{O}_{2}$, never evidenced as far as we know, is observed. 


\section{The role of zeolites $4 \mathrm{~A}$ on the radiolysis of water}

The hydrogen radiolytic yields measured in the system showing a significant release of hydrogen are presented in table 2. They are calculated considering the measurements before recombination when it happens, and taking into account the primary energy deposition in water.

When hydrogen is detected, the radiolytic yield calculated based on energy deposition in water is always higher than the one measured in free bulk water $\left(0.045 \mu \mathrm{mol} . \mathrm{J}^{-1}\right)$. This assessment has been done when zeolites are exposed to an external source of radiations ${ }^{19,23,25}$.

We first excluded the hypothesis that the organization of water, extremely immobilized in zeolites, could enhance its decomposition. Actually, the hydrogen radiolytic yields measured when ice water is irradiated $\left(0.007 \mu \mathrm{mol} . \mathrm{J}^{-1}\right.$ at $-196^{\circ} \mathrm{C}, 0.010 \mu \mathrm{mol} . \mathrm{J}^{-1}$ at $-100^{\circ} \mathrm{C}$ and 0.026 $\mu$ mol. $\left.\mathrm{J}^{-1} 30,31\right)$ is lower than the yield measured for liquid water at $25^{\circ} \mathrm{C}\left(0.045 \mu\right.$ mol. $\left.\mathrm{J}^{-1} 32\right)$. As a conclusion a higher crystalline organization seems to inhibit formation of $\mathrm{H}_{2}$ rather than enhancing it. 
Table 2: Hydrogen radiolytic yields and estimation of energy transfers, based on analysis results before recombination. $E_{\text {system }}$ is the quantity of energy deposited in the whole system (see experimental section for the calculation method). $E_{\text {water }}$ is calculated in agreement with the WLR.

\begin{tabular}{c|c|c|c|c|c|c|c|c|}
\multicolumn{4}{c}{} & \multicolumn{6}{c|}{ Low Volumetric Activity } & \multicolumn{5}{c|}{ High Volumetric Activity } \\
\hline $\begin{array}{c}\text { Water Loading } \\
\text { Ratio (\%) }\end{array}$ & 11.8 & 13.7 & 18.5 & 7.4 & 11.4 & 13.4 & 18.4 & 18.8 \\
\hline Cover gas & $\mathrm{Ar}$ & $\mathrm{Ar}$ & $\mathrm{Ar}$ & $\mathrm{Ar}$ & $\mathrm{Ar}$ & $\mathrm{Ar}$ & $\mathrm{Ar}$ & none \\
\hline $\begin{array}{c}\text { Hydrogen } \\
\text { Radiolytic Yield } \\
\left(\mu \mathrm{mol.} \mathrm{J}^{-1}\right)\end{array}$ & 0.09 & 0.10 & 0.10 & 0.08 & 0.07 & 0.12 & 0.11 & 0.10 \\
\hline$n_{\mathrm{H}_{2}}(\mu \mathrm{mol})$ & $1.4 \times 10^{-4}$ & $2.1 \times 10^{-4}$ & $7.1 \times 10^{-4}$ & $3.0 \times 10^{-5}$ & $1.3 \times 10^{-4}$ & $3.2 \times 10^{-4}$ & $1.0 \times 10^{-3}$ & $1.0 \times 10^{-3}$ \\
\hline$E_{\text {system }(\mathrm{kJ})}$ & 15.0 & 18.1 & 34.5 & 5.6 & 18.9 & 22.2 & 60.1 & 65.0 \\
\hline$E_{\text {water }}(\mathrm{kJ})$ & 1.6 & 2.2 & 6.8 & 0.4 & 1.9 & 2.6 & 9.3 & 10.3 \\
\hline$E_{\text {transferred }}(\mathrm{kJ})$ & 1.5 & 2.5 & 9.3 & 0.3 & 0.9 & 4.5 & 12.9 & 12.0 \\
\hline$E_{\text {transferred }}(\%)$ & 11.5 & 15.6 & 33.2 & 5.4 & 5.6 & 22.9 & 25.4 & 21.9
\end{tabular}

On the contrary, energy transfers from adsorbents to adsorbate, is a mechanism that could explain a higher quantity of hydrogen, released when water is adsorbed at an interface. The amount of energy transferred can be estimated, using the equation 3 and assuming that it is the only mechanism increasing hydrogen release ${ }^{28} \cdot n_{H_{2}}$ is the quantity of hydrogen released, $G_{H 2}$ in bulk water is the known radiolytic yield in bulk water, $E_{\text {primary deposited in water }}$ is the primary energy deposition in water and $E_{\text {transfered from zeolite to water }}$ is the energy transferred from zeolites to water.

$$
E_{\text {transfered from zeolite to water }}=\frac{n_{\mathrm{H}_{2}}}{G_{\mathrm{H} 2 \text { in bulk water }}}-E_{\text {primary deposited in water }}
$$


The quantity of energy transferred from zeolite to water, calculated from equation 3 , are reported in table 2 . They are calculated before recombination when it occurs. The ratio of energy transferred compared to energy deposited in the zeolites is also calculated and given as a percentage in table 2. This ratio increases when the loading ratio increases and seems also to be impacted by the volumetric activity. The same method was applied to quantify the energy transferred from $\mathrm{CeO}_{2}$ and $\mathrm{ZrO}_{2}$ to adsorbed water while some systems underwent irradiations ${ }^{28}$. The order of magnitudes of the energy transferred, ranging between 5.4 and $33.2 \%$ are consistent with the proportion of energy transferred during the radiolysis of water adsorbed on $\mathrm{CeO}_{2}$ and $\mathrm{ZrO}_{2}$, which are respectively of 4 and $18 \%{ }^{28}$. Consequently, the involvement of a transfer of energy from zeolites to adsorbed water is proposed as a first explanation to hydrogen and oxygen production enhancement.

As regard to the impact of the WLR, and considering the strong interaction between adsorbed water and the zeolite, the adsorption sites are foreseen to play an additional role to energy transfers. Amongst different species that can be implied in such an adsorption, hydroxyl radicals are often designed to play a major role on hydrogen release ${ }^{20,24}$. They should explain that we measured enhanced hydrogen radiolytic yields linked to the water loading ratio. An adsorption phenomenon of the latter, which could inhibit hydrogen recombination (equation 4) can be considered. Nevertheless, such a phenomenon would lead to a radiolytic yield decreasing with high number of free internal sites. Hydrogen release would be more efficient for lower loading ratio. Radiolytic yields tend to evolve in the opposite sense, indicating that this phenomenon, if it occurs, cannot be the major one.

$$
\mathrm{HO}^{\bullet}+\mathrm{H}_{2} \rightleftharpoons \mathrm{H}^{\bullet}+\mathrm{H}_{2} \mathrm{O}
$$

Except $\mathrm{H}_{2}$ and $\mathrm{O}_{2}$, an additional stable product of radiolysis can be released: $\mathrm{H}_{2} \mathrm{O}_{2}$. The production of $\mathrm{H}_{2} \mathrm{O}_{2}$, if it was not quantified, can also be discussed regarding the ratio between 
the amount of hydrogen and oxygen released by the water decomposition. It is always higher than 2, which could be an indicator of $\mathrm{H}_{2} \mathrm{O}_{2}$ production. Then, it decreases, which could indicate the dismutation of hydrogen peroxide occurring next. A dedicated study, experimental or simulated, is nevertheless required to deepen such a discussion.

Despite a high initial hydrogen radiolytic yield, we observed a recombination phenomenon happening next.

\section{The role of zeolites $4 \mathrm{~A}$ on the recombination of water}

From ten systems, a total recombination of $\mathrm{H}_{2}$ and $\mathrm{O}_{2}$ occurred in four unsaturated systems and is engaged in a fifth one. As far as we know, such a total recombination has not been observed yet, and hypothesis concerning partial recombination are often incomplete in the absence of information about other gases like $\mathrm{O}_{2}{ }^{19,25}$.

The average proportion of $\mathrm{H}_{2}$ and $\mathrm{O}_{2}$ reacting is 2.4 (the system loaded at $13.7 \%$ with LVA was not taken into account in this calculation as recombination is still ongoing, and $\mathrm{H}_{2}$ and $\mathrm{O}_{2}$ remain in the gaseous phase). There is no new species in the gaseous phase whose quantity of matter decreases. We considered a recombination leading to $\mathrm{H}_{2} \mathrm{O}_{2}$ or $\mathrm{H}_{2} \mathrm{O}$. In the first case, the ratio of $\mathrm{H}_{2}$ and $\mathrm{O}_{2}$ reacting would have been close to 1 , whereas in the second case, it would have been close to 2. We assume that the major product formed by the recombination of $\mathrm{H}_{2}$ and $\mathrm{O}_{2}$ is water. Combustion cannot explain the observations we made, because containers are free from ignition source, and because the recording of pressure revealed a reaction taking several days long. 
Table 3: Experimental conditions in which a total recombination between $\mathrm{H}_{2}$ and $\mathrm{O}_{2}$ is observed or engaged and characteristics of this recombination

\begin{tabular}{|c|c|c|c|c|}
\hline & $\begin{array}{c}\text { Low Volumetric } \\
\text { Activity }\end{array}$ & \multicolumn{3}{|c|}{ High Volumetric Activity } \\
\hline Water Loading Ratio (\%) & 11.8 & 7.4 & 11.4 & 13.4 \\
\hline $\begin{array}{l}\text { Delay before recombination } \\
\text { (days) }\end{array}$ & 300 & 80 & 175 & 210 \\
\hline \multicolumn{5}{|c|}{ Just before recombination } \\
\hline$n_{\mathrm{H}_{2}}(\mu \mathrm{mol})$ & $1.68 \times 10^{-4}$ & $7.13 \times 10^{-5}$ & $2.19 \times 10^{-4}$ & $3.57 \times 10^{-4}$ \\
\hline$n_{\mathrm{O}_{2}}(\mu \mathrm{mol})$ & $6.54 \times 10^{-5}$ & $3.13 \times 10^{-5}$ & $1.17 \times 10^{-4}$ & $1.31 \times 10^{-4}$ \\
\hline$E_{\text {system }}(\mathrm{kJ})$ & 15.0 & 5.6 & 18.9 & 26.6 \\
\hline$E_{\text {water }}(\mathrm{kJ})$ & 1.6 & 0.4 & 1.9 & 3.1 \\
\hline \multicolumn{5}{|c|}{ Evolution of gaseous phase during recombination } \\
\hline$\Delta n_{\mathrm{H}_{2}}(\mu \mathrm{mol}) \pm 10 \%$ & $1.16 \times 10^{-4}$ & $6.19 \times 10^{-5}$ & $2.19 \times 10^{-4}$ & $3.13 \times 10^{-4}$ \\
\hline$\Delta n_{\mathrm{O}_{2}}(\mu \mathrm{mol}) \pm 10 \%$ & $4.39 \times 10^{-5}$ & $3.05 \times 10^{-5}$ & $8.59 \times 10^{-5}$ & $1.27 \times 10^{-4}$ \\
\hline$\Delta n_{\mathrm{H}_{2}} / \Delta n_{\mathrm{O}_{2}} \pm 0.5$ & 2.6 & 2.0 & 2.5 & 2.5 \\
\hline
\end{tabular}

The reforming of water is delayed depending on the water loading ratio of the zeolites. Their implication is so evidenced. Moreover, for similar loading ratios (11.8 and 11.5 or 13.4 and $13.7 \%$ ) the delay before recombination also depends on the volumetric activity of the adsorbed water (table 3).

Based on the obvious influence of both volumetric activity of the adsorbed water and on the availability of the adsorption sites inside the zeolites we proposed a simple mathematical model linking the time before recombination to WLR and volumetric activity. This is an empirical 
approach to predict the delay before a recombination occurs in zeolite 4A / tritiated water systems, including the influence of the parameters discussed above.

As zeolites are seen as a catalyst in the recombination of water, it is more relevant to consider accessible adsorption sites or free volumes $(19.6-\mathrm{H})$, rather than directly taking into account the Water Loading Ratio (“H”).

Volumetric Activity also seems to play a major role. Some mechanisms proposed to describe isotopic exchange between $\mathrm{T}_{2}$ and $\mathrm{H}_{2} \mathrm{O}$ contain a step of initiation by Tritium-induced radiations ${ }^{33,34}$. Based on this assumption, we introduced the proper activity of each system in our numerical model, presented on figure 8 and depicted by the equation $5 . \Delta t_{\text {recombination }}$ is the delay before a recombination is observed, $\mathrm{H}$ is the WLR of zeolites and $A_{\text {volumic }}$ the volumetric activity.

$$
\Delta t_{\text {recombination }}=\frac{K}{(19.6-H) \times A_{\text {volumic }}}
$$

The experimental results obtained with the four systems included in table 3 were fit using the equation 5. The value calculated for the fitting constant $\mathrm{K}$ is: $7.2 \times 10^{4} \pm 1.1 \times 10^{4}$ days. TBq. $\mathrm{L}^{-}$ 1 .

According to this model, a recombination is expected in the three remaining systems showing significant release of $\mathrm{H}_{2}$ and $\mathrm{O}_{2}$. The system loaded at $13.7 \%$ with LVA water, not included to build the numerical model, gives a first validation of this one, with a slight decrease of $\mathrm{H}_{2}$ and $\mathrm{O}_{2}$ between 398 and 439 days, and a significant decrease of the total quantity of gas confirmed after 450 days, matching the predicted delay. 


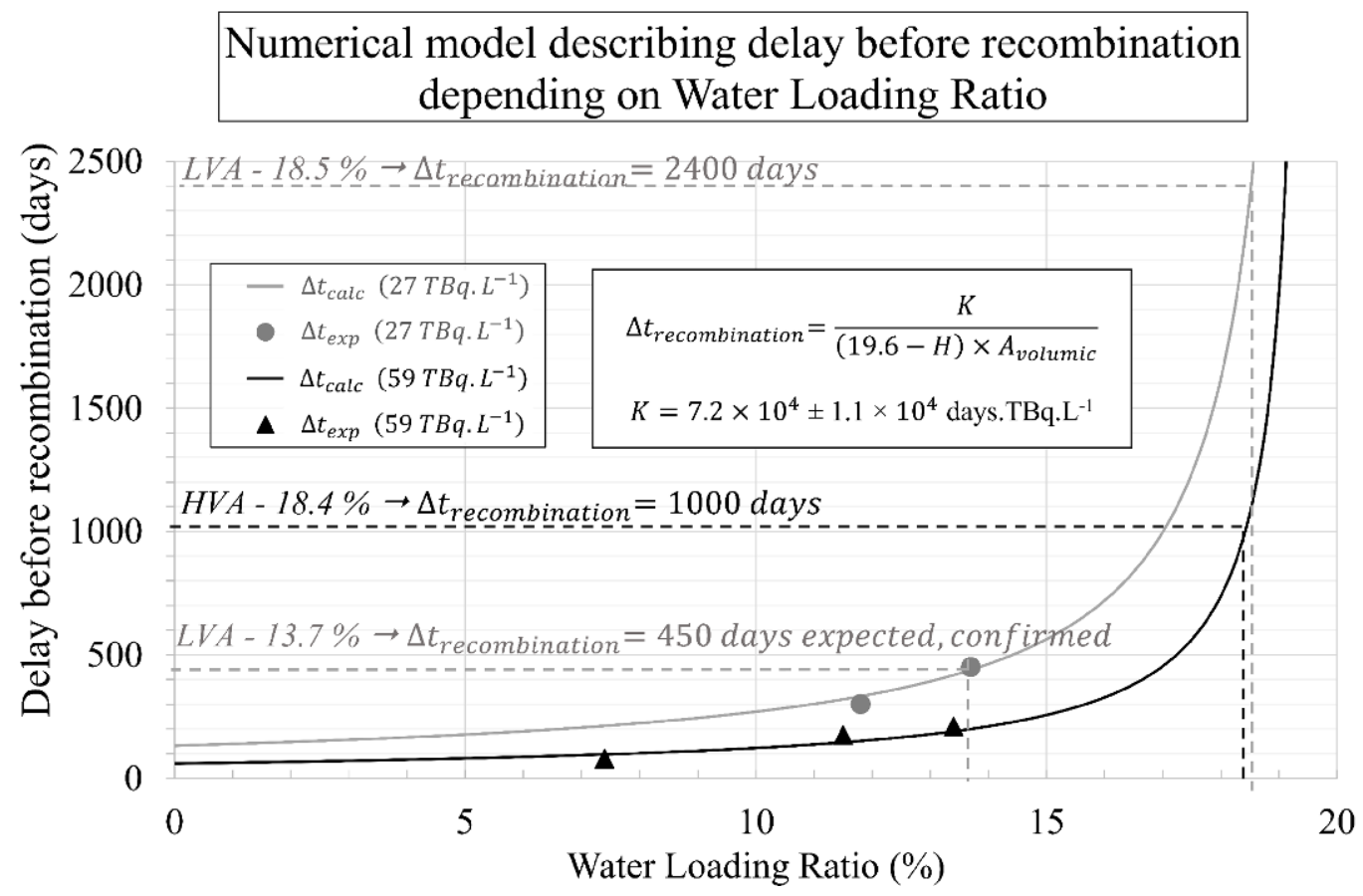

Figure 8: Simple numerical model, linking the time observed before recombination and the water loading ratio, taking into account the volumetric activity of adsorbed water.

The absence of hydrogen and oxygen recombination when zeolites are saturated with water is depicted by the model and so far in agreement with the experimental results. It corroborates the hypothesis of a catalytic role of zeolites $4 \mathrm{~A}$ on $\mathrm{H}_{2}$ and $\mathrm{O}_{2}$ recombination, implying the internal adsorption sites of microporous volumes. The models used to describe free bulk water radiolysis count two major reactions leading both to $\mathrm{H}_{2}$ and $\mathrm{O}_{2}$ consumption and to $\mathrm{H}_{2} \mathrm{O}$ production (equation 6 and 7).

The surface adsorption of $\mathrm{e}^{-}$aq and $\mathrm{HO}^{\circ}$ could explain a threshold observation, corresponding to the saturation of surfaces with adsorbed species. Despite, the saturation would be reached first 
for the highest water loading ratios. On the contrary, recombination happens first in our lowest loaded systems.

So, the threshold that we observed for recombination of water is preferentially associated to diffusion kinetics. Zeolites are first designed to slow down the diffusion of species because of the reduced diameter of cavities and of channels formed. Moreover, the adsorption of water in those volumes, and its organization induced by the interaction between zeolite and water, are supposed to slow down the migration of all radiolytic species through the zeolite. A dependency of the diffusion kinetics on the WLR makes then sense and could at least partially explained the delay observed before recombination.

\section{CONCLUSION}

The study of gas released during one year of self-radiolysis of tritiated water showed a major role of zeolites $4 \mathrm{~A}$ on radiolysis. They first favor the decomposition of tritiated water. A transfer of energy from the zeolite to water is identified as a possible and realistic phenomenon to explain the enhancement of water decomposition. Furthermore, the adsorption of hydroxyl radicals on internal adsorption sites of zeolites has been considered and could be deepened. Then zeolites favor a total recombination, not observed in the case of free bulk water, or in the case of external radiations. The quantization of $\mathrm{H}_{2}$, but also of $\mathrm{O}_{2}$, let us think that they react to restore water. Recombination is delayed by a low volumetric activity of loaded water or by an important water loading ratio. Based on those two observations, a simple empirical model has been proposed to predict the recombination depending on water loading ratio and activity. It is an empirical approach, based on the quantified influence of the activity of tritiated water and on the water loading ratio. Once more, the link between the phenomenon observed and the water loading ratio 
of zeolites is an indicator of their influence. The observation of a threshold for recombination of water without a clear return to radiolysis at this time, allows proposing a phenomenon of saturation involving the diffusion of reactive species after a given time.

To complete this understanding, simulation tools appear to be a relevant support, to study the reactivity of radiolytic species in the surrounding of adsorption sites or to perform calculations on diffusion kinetics in zeolites $4 \mathrm{~A}$ at different loading ratios. From an experimental point of view, pursuing the ongoing experiment will necessary provide additional information and allow attributing the release and recombination of $\mathrm{H}_{2}$ and $\mathrm{O}_{2}$ to a cyclic or a threshold phenomenon. Additional loading ratio or volumetric will also lead to deepen the mathematical description proposed, that showed to be a good support for both the understanding and the prediction of the radiolysis of self tritiated water adsorbed in zeolites $4 \mathrm{~A}$.

\section{ACKNOWLEDGMENT}

CEA (Commissariat à l'Energie Atomique et aux Energies Alternatives) is acknowledged for financial support for this research project. The Laboratoire Interdisciplinaire Carnot de Bourgogne is also thanked for the help in understanding better zeolites behavior.

AUTHOR INFORMATION

\section{Corresponding Author}

* laetitia.frances@,kit.edu 


\section{Author Contributions}

The manuscript was written through contributions of all authors. All authors have given approval to the final version of the manuscript. $\dagger \ddagger$ These authors contributed equally.

\section{ABBREVIATIONS}

WLR: Water Loading Ratio

LVA: Low Volumetric Activity

HVA: High Volumetric Activity

\section{REFERENCES}

(1) Baerlocher, C.; McCusker, L.B.; Olson, D.H. Atlas of Zeolites Framework, Sixth Revised Edition; Elsevier, 2007.

(2) Hemelsoet, K.; Lesthaeghe, D.; Van Speybroeck, V.; Waroquier, M. Global DFT-Based Reactivity Indicators: An Assessment of Theoretical Procedures in Zeolite Catalysis. $J$. Phys. Chem. C 2007, 111, 3028-3037.

(3) Iwase, Y.; Sakamoto, Y.; Shiga, A.; Miyaji, A.; Motokura, K.; Koyama, T.; Baba, T. Shape-Selective Catalysis Determined by the Volume of a Zeolite Cavity and the Reaction Mechanism for Propylene Production by the Conversion of Butene Using a ProtonExchanged Zeolite. J. Phys. Chem. C 2012, 116, 5182-5196.

(4) Montanari, T.; Busca, G. On the Mechanism of Adsorption and Separation of $\mathrm{CO}_{2}$ on LTA Zeolites: An IR Investigation. Vib. Spectrosc. 2008, 46, 45-51.

(5) Zhu, W.; Gora, L.; Van den Berg, A. W. C.; Kapteijn, F.; Jansen, J. C.; Moulijn, J. A. Water Vapour Separation from Permanent Gases by a Zeolite-4A Membrane. J. Membr. Sci. 2005, 253, 57-66.

(6) Kotoh, K.; Takashima, S.; Nakamura, Y. Molecular-sieving Effect of Zeolite 3A in Adsorption of $\mathrm{H}_{2}$, HD, $\mathrm{D}_{2}$. Fusion Eng. Des. 2009, 84, 1108-1112.

(7) Pamela, J.; Bottereau, J.-M.; Canas, D.; Decanis, C.; Liger, K.; Gaune, F. ITER Tritiated Waste Management by the Host State and First Lessons Learned for Fusion Development. Fusion Eng. Des. 2013, 89, 2001-2007.

(8) Breck, D. W. Zeolite molecular sieves: Structure, Chemistry, and Use; Wiley, 1974.

(9) Demontis, P.; Gulín-González, J.; Jobic, H.; Masia, M.; Sale, R.; Suffritti, G. B. Dynamical Properties of Confined Water Nanoclusters: Simulation Study of Hydrated Zeolite NaA: Structural and Vibrational Properties. ACS Nano. 2008, 2, 1603-1614. 
(10) Crupi, V.; Longo, F.; Majolino, D.; Venuti, V. T Dependence of Vibrational Dynamics of Water in Ion-exchanged Zeolites A: A Detailed Fourier Transform Infrared Attenuated Total Reflection Study. J. Chem. Phys. 2005, 123, 154702.

(11) Faux, D. A.; Smith, W.; Forester, T. R. Molecular Dynamics Studies of Hydrated and Dehydrated Na ${ }^{+}$-Zeolite-4A. J. Phys. Chem. B 1997, 101, 1762-1768.

(12) Moïse, J. C.; Bellat, J. P.; Méthivier, A. Adsorption of Water on X and Y Zeolites Exchanged with Barium. Microporous Mesoporous Mater. 2001, 43, 91-101.

(13) Crupi, V.; Majolino, D.; Migliardo, P.; Venuti, V.; Wanderlingh, U. A FT-IR Absorption Analysis of Vibrational Properties of Water Encaged in NaA Zeolites: Evidence of a Structure Maker Role of Zeolitic Surface. Eur. Phys. J. E - Soft Matter 2003, 12, 55-58.

(14) Schmid, T. E.; Dollinger, G.; Hable, V.; Greubel, C.; Zlobinskaya, O.; Michalski, D.; Molls, M.; Röper, B. Relative Biological Effectiveness of Pulsed and Continuous $20 \mathrm{MeV}$ Protons for Micronucleus Induction in 3D Human Reconstructed Skin Tissue. Radiother. Oncol. J. Eur. Soc. Ther. Radiol. Oncol. 2010, 95, 66-72.

(15) Terryn, H.; Maquille, A.; Houeelevin, C.; Tilquin, B. Irradiation of Human Insulin in Aqueous Solution, First Step towards Radiosterilization. Int. J. Pharm. 2007, 343, 4-11.

(16) Katayama, T.; Nakauma, M.; Todoriki, S.; Phillips, G. O.; Tada, M. Radiation-induced Polymerization of Gum Arabic (Acacia Senegal) in Aqueous Solution. Food Hydrocoll. 2006, 20, 983-989.

(17) Collinson, E.; Kroh, J.; Dainton, F. S. The Radiation Chemistry of Aqueous Solutions. II. Radical and Molecular Yields for Tritium Beta-Particles. Proc. R. Soc. Math. Phys. Sci. 1962, 265, 422-429.

(18) Stolz, T.; Ducret, D.; Heinze, S.; Baldacchino, G.; Colson, J.-C.; Dedieu, B.; Pelletier, T. Self Radiolysis of Tritiated Water. Fusion Eng. Des. 2003, 69, 57-60.

(19) Nakashima, M.; Aratono, Y. Radiolytic Hydrogen Gas Formation from Water Adsorbed on Type A Zeolites. Radiat. Phys. Chem. 1993, 41, 461-465.

(20) Foley, S.; Rotureau, P.; Pin, S.; Baldacchino, G.; Renault, J.-P.; Mialocq, J.-C. Radiolysis of Confined Water: Production and Reactivity of Hydroxyl Radicals. Angew. Chem. Int. Ed. 2005, 44, 110-112.

(21) Le Caër, S.; Rotureau, P.; Brunet, F.; Charpentier, T.; Blain, G.; Renault, J.-P.; Mialocq, J.-C. Radiolysis of Confined Water: Hydrogen Production at a High Dose Rate. ChemPhysChem 2005, 6, 2585-2596.

(22) Musat, R. M.; Cook, A. R.; Renault, J.-P.; Crowell, R. A. Nanosecond Pulse Radiolysis of Nanoconfined Water. J. Phys. Chem. C 2012, 116, 13104-13110.

(23) Frances, L.; Grivet, M.; Renault, J.-P.; Groetz, J.-E.; Ducret, D. Hydrogen Radiolytic Release from Zeolite 4A/Water Systems under $\gamma$ Irradiations. Radiat. Phys. Chem. 2015, 110, 6-11.

(24) Yamada, R.; Kumagai, Y. Effects of Alumina Powder Characteristics on $\mathrm{H}_{2}$ and $\mathrm{H}_{2} \mathrm{O}_{2}$ Production Yields in Gamma Radiolysis of Water and $0.4 \mathrm{M} \mathrm{H}_{2} \mathrm{SO}_{2}$ Aqueous Solution. Int. J. Hydrogen Energy 2012, 37, 3272-3277.

(25) Nakashima, M.; Tachikawa, E. Radiolytic Gas Production from Tritiated Water Adsorbed on Molecular Sieve 5A. J. Nucl. Sci. Technol. 1987, 24, 41-46.

(26) Langmi, H. W.; Walton, A.; Al-Mamouri, M. M.; Johnson, S. R.; Book, D.; Speight, J. D.; Edwards, P. P.; Gameson, I.; Anderson, P. A.; Harris, I. R. Hydrogen Adsorption in Zeolites A, X, Y and RHO. J. Alloys Compd. 2003, 356-357, 710-715. 
(27) MacMahon, D. Half-life Evaluations for 3H, 90Sr, and 90Y. Appl. Radiat. Isot. 2006, 64, 1417-1419.

(28) LaVerne, J. A.; Tandon, L. $\mathrm{H}_{2}$ Production in the Radiolysis of Water on $\mathrm{CeO}_{2}$ and $\mathrm{ZrO}_{2}$. J. Phys. Chem. B 2002, 106, 380-386.

(29) LaVerne, J. A.; Tonnies, S. E. $\mathrm{H}_{2}$ Production in the Radiolysis of Aqueous $\mathrm{SiO}_{2}$ Suspensions and Slurries. J Phys Chem B 2003, 107, 7277-7280.

(30) Ghormley, J. A.; Stewart, A. C. Effects of $\gamma$-Radiation on Ice. J. Am. Chem. Soc. 1956, 78, 2934-2939.

(31) Siegel, S.; Rennick, R. Isotope Effects in the $77^{\circ} \mathrm{K} \gamma$ Irradiation of Ice. J. Chem. Phys. 1966, 45, 3712-3720.

(32) Schwarz, H. A.; Losee, J. P.; Allen, A. O. Hydrogen Yields in the Radiolysis of Aqueous Solutions. J. Am. Chem. Soc. 1954, 76, 4693-4694.

(33) Slattery, M. W.; Ingraham, N. L. Detritiation of Water by Isotopic Exchange: Experimental Results. Environ. Sci. Technol. 1994, 28, 1417-1421.

(34) Yang, J. Y.; Gevantman, L. H. Tritium $\beta$-Radiation-Induced Isotopic Exchange with Water Vapor. J. Phys. Chem. 1964, 68, 3115-3119. 
GRAPHICAL TABLE OF CONTENT

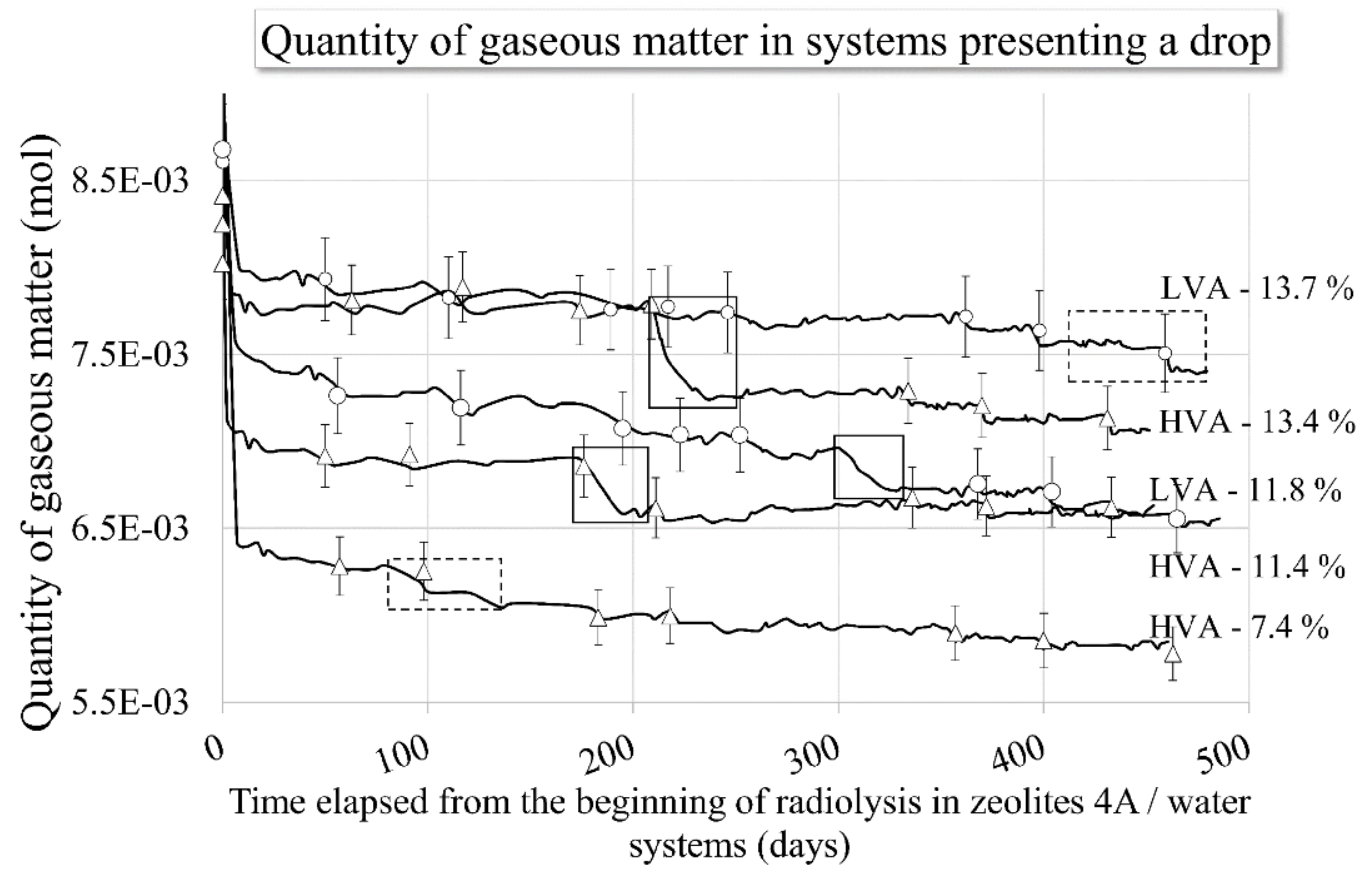

